
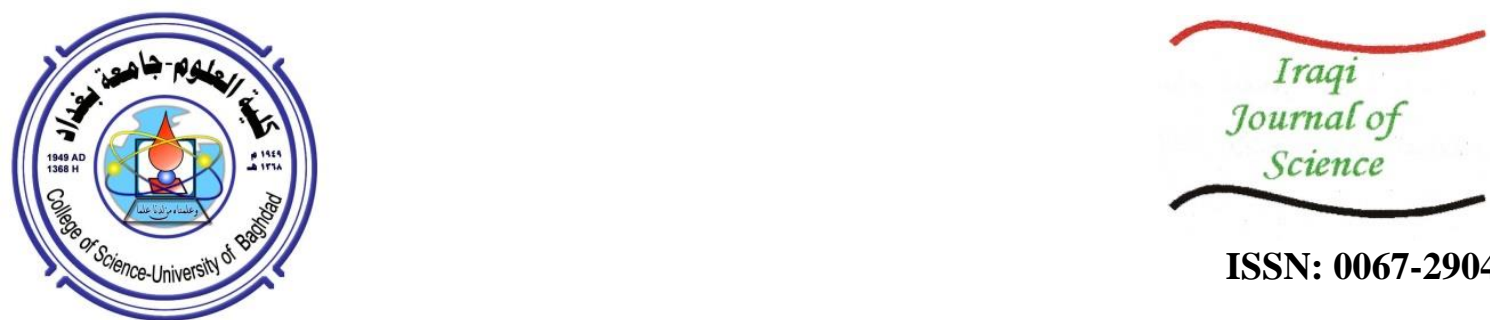

ISSN: 0067-2904

\title{
Effects of Gum Arabic-Coated Magnetite Nanoparticles on the Removal of Pb Ions from Aqueous Solutions
}

\author{
Hanan J. Mustafa, Tagreed M. Al-Saadi* \\ Department of Physics, College of Education for Pure Science (Ibn Al-Haitham)/University of Baghdad, \\ Baghdad, Iraq
}

Received: 22/3/2020

Accepted: $22 / 6 / 2020$

\begin{abstract}
To study the removal of lead $(\mathrm{Pb})$ ions from aqueous solutions, novel magnetite nanoparticles (NPs) of $\mathrm{Ni}_{0.31} \mathrm{Mg}_{0.15} \mathrm{Ag}_{0.04} \mathrm{Fe}_{2.5} \mathrm{O}_{4}$ were synthesized by coprecipitation synthesis using metal sulfates, and then coated with Gum Arabic (GA). The prepared NPs were analyzed using various spectroscopic and analytical methods, such as X-Ray diffraction analysis (XRD), Field Emission Scanning Electron Microscopy (FE-SEM), Energy Dispersive X-ray spectroscopy (EDX), Fourier Transform Infra-Red spectroscopy (FT-IR), and Atomic Absorption Spectrophotometer (AAS). By using XRD analysis, the cubic inverse spinel structure of the prepared NPs was proven, showing average values of crystallite size, lattice constant, and density of $28.57 \mathrm{~nm}, 8.32582 \AA$, and $5.2890 \mathrm{~g} / \mathrm{cm}^{3}$, respectively. FE-SEM analysis revealed the sphere-like shape of the nanoparticles with a measured crystallite size of $25.93 \mathrm{~nm}$. The existence of constituent elements was evidenced by EDX. FT-IR test proved the success of the coating process of magnetite NPs by the presence of the main characteristic absorption bands of GA in the FT-IR spectrum of GA-magnetite NPs. The adsorption of $\mathrm{Pb}$ ions by GAmagnetite NPs was shown by AAS analysis, where the concentration of $\mathrm{Pb}$ ions decreased from $25 \mathrm{ppm}$ to $6.6 \mathrm{ppm}$, reaching $1.1 \mathrm{ppm}$ at the time of $25 \mathrm{~min}$. The porosity of the NPs and the carboxyl groups in GA played an important role in the process.
\end{abstract}

Keywords: Gum Arabic, Magnetite Nanoparticles, $\mathrm{Pb}$ ions, Ferrite, co-precipitation

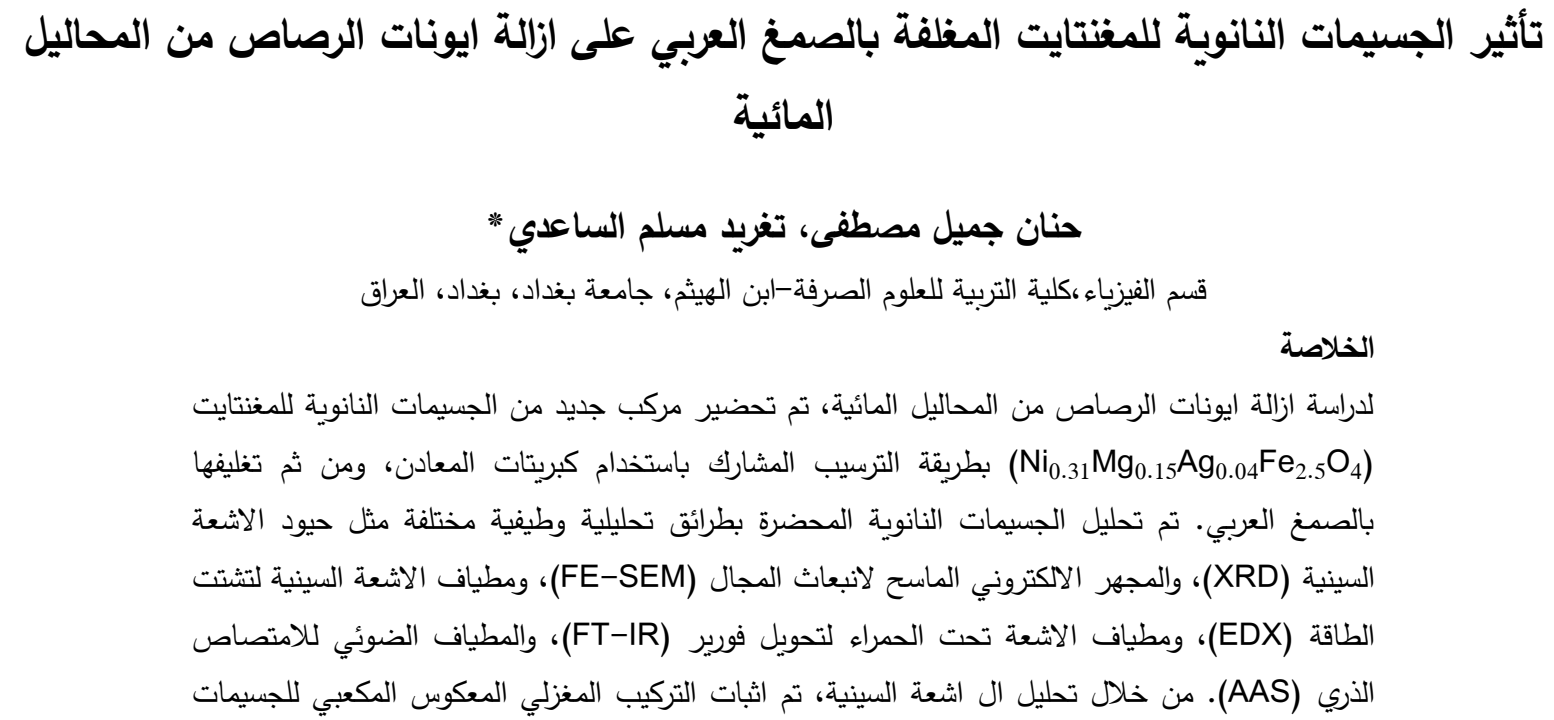

*Email: a_cute_physics@yahoo.com 


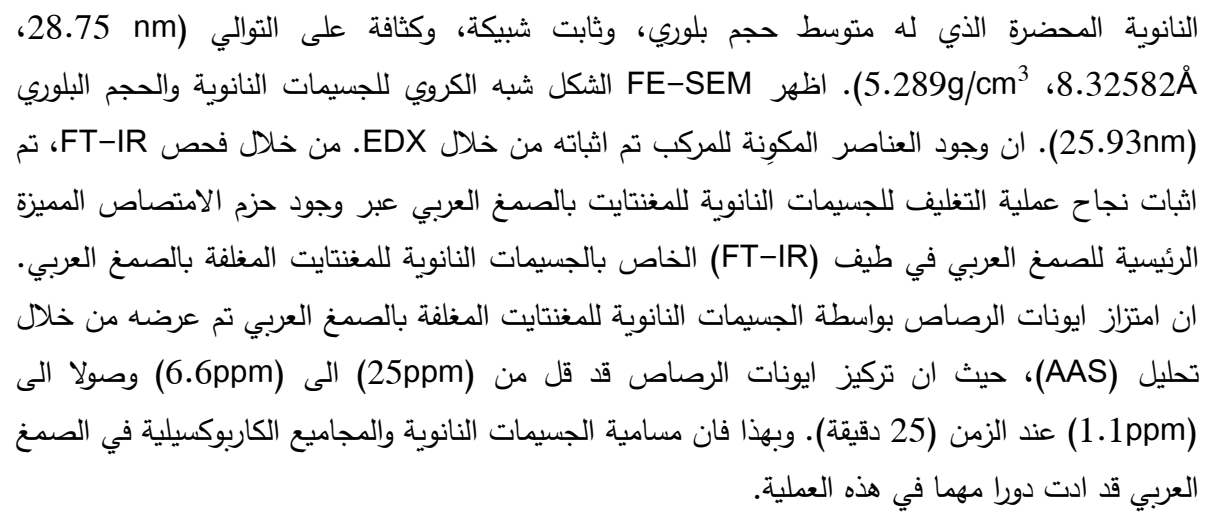

\section{Introduction}

Serious environmental and health problems are caused by the contamination with heavy metals, such as zinc, lead, cadmium, etc. Various processes are being the cause of water contamination with $\mathrm{Pb}$ ions, such as manufacturing, mining, and smelting, which give rise to plenty of effects that are dangerous to human beings. The issue that matters is that metals have degradation resistance and eventually accumulate in living organisms. The contamination with heavy metal ions is a serious problem due to their toxic effects on different forms of life [1].

Removal of different pollutants from wastewater has recently been under ongoing investigation by using several processes [2]. The most important methods used to clean wastewater from metal ions include adsorption, ion exchange, membrane filtration, flotation, chemical precipitation, and electrolytic methods [3]. Various nanomaterials present different advantages for the removal of heavy metals and exert functional operation properties, including high surface area, surface chemistry, and enormous amount of particles, surface interactions, and magnetic separation. Their special capability of adsorbing is another essential characteristic that enables nanomaterials to assist in heavy metal ions removal. A substantial number of studies have been applied on nanomaterials to test their potency to eliminate heavy metal ions from wastewater. The results revealed their excellent capability of metal ions adsorption from contaminated water [4]. Adsorption is a simple, relatively low-cost, and effective method utilized to remove metal ions from wastewater, which showed higher efficiency than the other techniques [5].

During the past decades, a large number of studies concentrated on magnetite nanoparticles to eliminate wastewater contaminants due to their adsorption strength, high magnetization, special electrical characteristics, and low toxicity. Magnetic nanoparticles are particularly suitable for heavy metals adsorption from wastewater. There is a strong magnetic moment in iron atom due to the existence of unpaired electrons in the orbital 3d [6]. Magnetic nanoparticles have a great ability of aggregation. Therefore, surface modulation of functional groups is necessary to improve the stability of magnetite nanoparticles [5], enhance their physicochemical features, to accomplish different kinds of applications [7].

Gum Arabic (Figure-1) is a natural exudate that belongs to a species of Acacia Senegal obtained from the trees of Acacia Seyal and Acacia Senegal in Africa [8]. It is a widely utilized component in food and medicinal industries, in dairy products, confectionery, beverages, gummy candies, ink, textiles, liquid adhesives, paints, cosmetics, and pharmaceutical products $[9,10]$. GA is a non-toxic, hydrophilic, negatively charged, branch-chained, complex polysaccharide connected to a mixture of potassium, magnesium, and calcium salts [11]. GA has been utilized by many groups in drug delivery systems [12], as carriers in the micro-encapsulation of bioactive molecules [13], and in the nanotechnology field [14]. This is because it becomes biocompatible and stabilized in nanostructures [7]. Recently, GA has been investigated by in vitro and in vivo studies for coating and increasing biocompatibility of magnetic nanoparticles of iron oxide NPs [15], gold NPs [16], carbon nanotubes [17], and quantum dot nanocolloids [18].

This biopolymer represents a good and appealing alternative as an adsorbent due to its high reactivity, good physicochemical characteristics, excellent selectivity towards aromatic compounds and metals, and chemical stability resulting from the existence of chemically reactive groups (hydroxyl, acetamido, or amino groups) in polymer chains. Moreover, the polysaccharide contained in Gum Arabic has the ability to bond by chemical and physical interactions with a wide variety of 
species. Hence, adsorption on polysaccharide derivatives can be a low-cost procedure of choice in water decontamination for compounds extraction and separation and a useful tool for preserving the environment [19].

This research aims to study the effects of coating of synthesized magnetite NPs with Gum Arabic on the removal of $\mathrm{Pb}$ ions from aqueous solution by adsorption process.

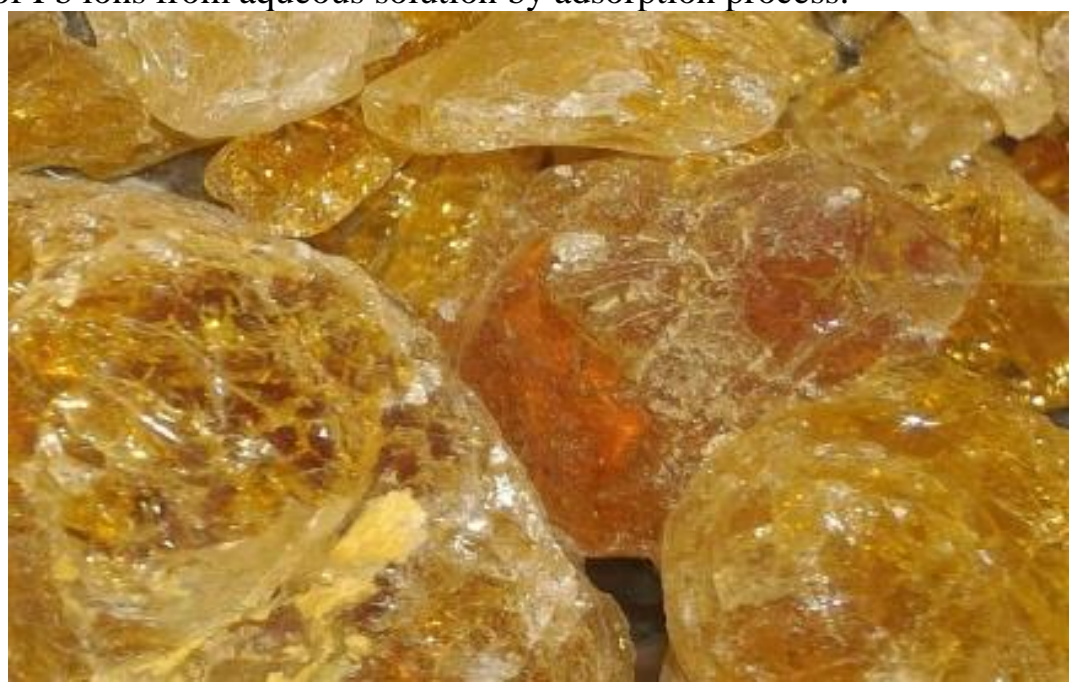

Figure 1-Image of gum Arabic

\section{Materials and Methods}

\subsection{Materials}

The nanoparticles powder of magnetite was synthesized by using metal sulfates. These sulfates included ferrous sulfate $\left(\mathrm{FeSO}_{4} .7 \mathrm{H}_{2} \mathrm{O}, 99.0 \%\right)$, pure nickel sulfate -6-hydrate $\left(\mathrm{NiSO}_{4} \cdot 6 \mathrm{H}_{2} \mathrm{O}, 99.0 \%\right)$, magnesium sulfate heptahydrate $\mathrm{AR}\left(\mathrm{MgSO}_{4} \cdot 7 \mathrm{H}_{2} \mathrm{O}, 99.5 \%\right)$, and silver sulfate $\left(\mathrm{Ag}_{2} \mathrm{SO}_{4}, 99.0 \%\right)$. The powder also included potassium nitrate $\left(\mathrm{KNO}_{3}, 99.9 \%\right)$, potassium hydroxide $(\mathrm{KOH}, 99.5 \%)$, and $\mathrm{GA}$ from the local market.

\subsection{Preparation}

$\mathrm{Ni}_{0.31} \mathrm{Mg}_{0.15} \mathrm{Ag}_{0.04} \mathrm{Fe}_{2.5} \mathrm{O}_{4}$ magnetite NPs were synthesized by the co-precipitation method, as described by Jawaher et al. [20]. A concentration of $0.12 \mathrm{M}$ of the used sulfates $\left(\mathrm{FeSO}_{4} \cdot 7 \mathrm{H}_{2} \mathrm{O}\right.$, $\mathrm{MgSO}_{4} .7 \mathrm{H}_{2} \mathrm{O}, \mathrm{NiSO}_{4} \cdot 6 \mathrm{H}_{2} \mathrm{O}$, and $\left.\mathrm{Ag}_{2} \mathrm{SO}_{4}\right)$ was dissolved in deionized water $(50 \mathrm{ml}) . \mathrm{KNO}_{3}(1.01 \mathrm{~g})$ was dissolved in deionized water $(10 \mathrm{ml})$ and added to the former solution, which was then stirred for $30 \mathrm{~min}$. After that, $\mathrm{KOH}(1.402 \mathrm{~g})$ was dissolved in $10 \mathrm{ml}$ of deionized water and slowly added to the last solution. The final reaction mixture was heated until the temperature reached $100^{\circ} \mathrm{C}$, then kept at this temperature for $2 \mathrm{~h}$; the precipitate was cooled down to room temperature, washed with deionized water several times, and dried at $50^{\circ} \mathrm{C}$ overnight. Finally, the prepared magnetite NPs were sintered at $600^{\circ} \mathrm{C}$ for $2 \mathrm{~h}$.

\subsection{Coating}

The coating procedure was accomplished as mentioned earlier [20], except that the ratio of magnetite NPs to the coating material was 1:6 due to the experiment conditions. Gum arabic was first washed with deionized water, then left to dry at room temperature, ground by an electrical grinder, and sieved. A weight of $6 \mathrm{~g}$ of GA powder was dissolved in $200 \mathrm{ml}$ of deionized water, then $1 \mathrm{~g}$ of magnetite NPs was added. The mixture was blended for $1 \mathrm{hr}$ by an electric hand mixer. As a result of the gum nature, foam was formed at the top of the mixture and some of the magnetite NPs were suspended in this foam. Thus, the mixture was covered and left for 1 day to let the particles settle down. The mixture was then washed with deionized water several times and left to dry at room temperature.

\subsection{Characterization of magnetite NPs}

The crystallographic structure of the synthesized magnetite NPs was examined by XRD (XRD6000 Shimadzu) with a $\mathrm{Cu}$ target of $\lambda=1.54 \AA$ and an angle of $2 \theta=20-80$ degree. The surface characteristics of the NPs were observed utilizing FE-SEM (Tescan MIRA3) equipped with EDX spectroscopy. Magnetite NPs were also characterized by FTIR spectrophotometer (IRPrestige-21 
Shimadzu). Pb ion concentrations were measured by atomic absorption spectrophotometer (AA-7000 Shimadzu).

\subsection{Removal of $\mathrm{Pb}$ ions}

The adsorption of $\mathrm{Pb}$ ions was achieved in aqueous solutions in a water bath shaker at $30^{\circ} \mathrm{C}$ and $100 \mathrm{rpm}$. The dosage of magnetite NPs utilized in this study was $0.1 \mathrm{~g}$ for different contact times (5, $10,15,20, \& 25 \mathrm{~min})$. Each sample was prepared in a round bottom flask of $50 \mathrm{ml}$ containing $25 \mathrm{ppm}$ of $\mathrm{Pb}$ ions. Magnetite NPs were removed from the solution by a magnet after finishing the adsorption process. The solution was tested by atomic adsorption spectrometer (AA-7000, Shimadzu) for detecting $\mathrm{Pb}$ ion concentration remained after the completion the of adsorption process.

\section{Results and Discussion}

XRD pattern of the synthesized magnetite NPs is illustrated in Figure-2. The structural properties were studied in the range of $20-80^{\circ} \mathrm{C}$. This diffraction pattern clearly coincides with the standard pattern of the cubic spinel magnetite phase JCPDS no. (19-0629) [21]. The remarkable peaks of the synthesized magnetite NPs were indexed to the crystal planes of the cubic inverse spinel iron oxide $\left(\mathrm{Fe}_{3} \mathrm{O}_{4}\right)$, which were found to be (220), (311), (400), (422), (511), and (440), corresponding to the diffraction angles $30.22^{\circ}, 35.68^{\circ}, 43.38^{\circ}, 54.10^{\circ}, 57.16^{\circ}$, and $62.56^{\circ}$, respectively. Also, there is an appearance of extra peaks than those of $\mathrm{Fe}_{3} \mathrm{O}_{4}$, which are attributed to other phases of iron oxide (cubic $\gamma-\mathrm{Fe}_{2} \mathrm{O}_{3}$ and tetragonal $\gamma-\mathrm{Fe}_{2} \mathrm{O}_{3}$ (incomplete)); these phases appear as a result of the sintering process, where cubic $\gamma-\mathrm{Fe}_{2} \mathrm{O}_{3}$ appears at $200^{\circ} \mathrm{C}$, while tetragonal $\gamma-\mathrm{Fe}_{2} \mathrm{O}_{3}$ appears at $600^{\circ} \mathrm{C}$ [22]. The average crystallite size of the synthesized magnetite NPs was $28.57 \mathrm{~nm}$, as calculated using the Debye Scherrer's formula below [23].

$$
D=\frac{0.9 \lambda}{\beta \cos \theta}
$$

where $\lambda$ is the wavelength of the $\mathrm{x}$-ray and $\beta$ is the FWHM in radians.

It is worth stating that only magnetite particles having a particle size less than $30 \mathrm{~nm}$ exhibit super paramagnetic properties and have a large surface area that renders them prone to magnetic fields, without an external magnetic field to support them; they do not become permanently magnetized. These properties are highly useful in the development of the novel separation process [24].

The lattice parameter value was calculated using Rietveld refinement software and it is found to be $8.32582 \AA$. In addition, the $\mathrm{x}$-ray density was calculated using equation (2) and has a value of 5.2890 $\left(\mathrm{g} / \mathrm{cm}^{3}\right)[25]$.

$$
\rho=\frac{8 M_{w}}{N_{A} \cdot a^{3}}
$$

where $M_{w}$ is the molecule weight, $N_{A}$ is Avogadro's number, and a is lattice constant.

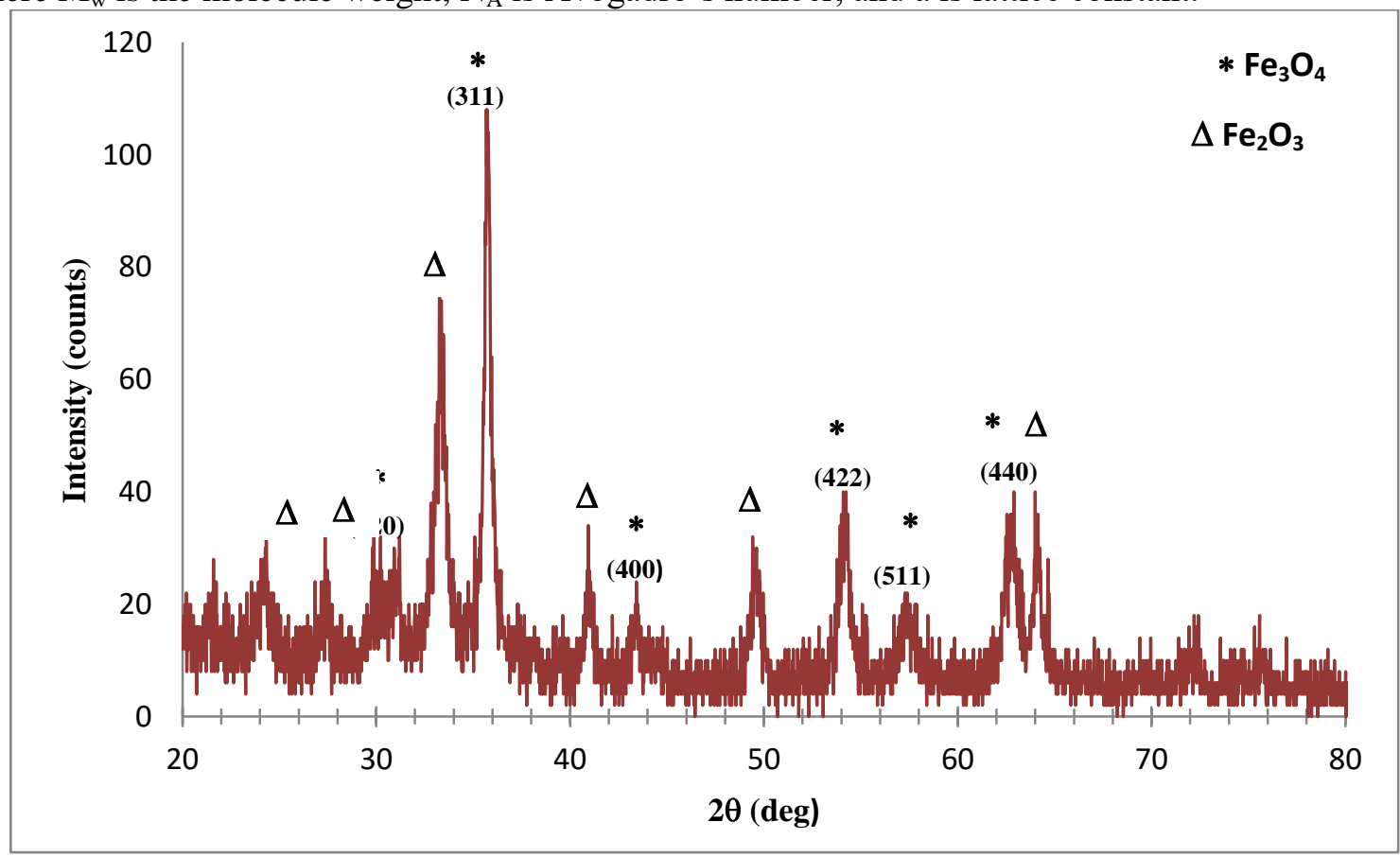

Figure 2-XRD pattern of the $\mathrm{Ni}_{0.31} \mathrm{Mg}_{0.15} \mathrm{Ag}_{0.04} \mathrm{Fe}_{2.5} \mathrm{O}_{4}$ magnetite NPs 
The FE-SEM imaging of the synthesized $\mathrm{Ni}_{0.31} \mathrm{Mg}_{0.15} \mathrm{Ag}_{0.04} \mathrm{Fe}_{2.5} \mathrm{O}_{4}$ magnetite NPs at a resolution limit of 200nm is shown in Figure-(3-a). The homogeneity and uniformity of the synthesized NPs can be noticed from this figure. They have a sphere-like shape and are distributed regularly. Figure- (3-a) also proves that the synthesized NPs are in the nanometer range, having an average particle size of $25.93 \mathrm{~nm}$, which is very close to that calculated by Debye Scherrer's formula. The high porosity of the synthesized NPs is remarkable, which increases the capacity of ion adsorption on the nanomaterial surface. As observed in Figure- (3-a), there are some agglomerations of nanoparticles; this is due to the sintering processes. In addition, the nanoparticles possess high surface energies, hence they tend to agglomerate and grow to larger assemblies [26].

Figure- (3-b) shows EDX peaks of the synthesized magnetite nanoparticles. The observed peaks present the existence of the elements $\mathrm{O}, \mathrm{Fe}, \mathrm{Ni}, \mathrm{Mg}$, and $\mathrm{Ag}$ and have the following energies spectra in keV: (O: $\mathrm{K} \alpha=0.525),(\mathrm{Fe}: \mathrm{K} \alpha=6.4, \mathrm{~L} \alpha=0.705),(\mathrm{Ni}: \mathrm{K} \alpha=7.84, \mathrm{~L} \alpha=0.85),(\mathrm{Mg}: \mathrm{K} \alpha=1.25)$, and (Ag: $\mathrm{L} \alpha=2.98, \mathrm{~L} \beta=3.35$ ). The figure does not show $\mathrm{K} \alpha$ for $\mathrm{Ag}$, since it appears at $22.16 \mathrm{keV}$ and the devices is limited to $10 \mathrm{keV}$. There are other spectra than those of the constituent elements, identified at the energies of 1.77 and $2.3 \mathrm{keV}$. These are false peaks that appeared in the EDX spectra as a consequence of the automatic peak identification process. This process is sensitive to noise in the Xray continuum that forms the spectral background because the random groupings of background counts can mimic a characteristic peak [27].

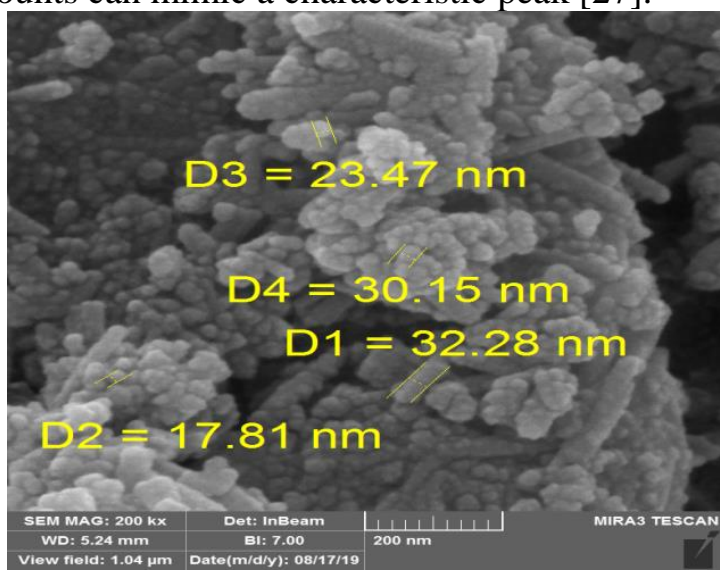

(a)

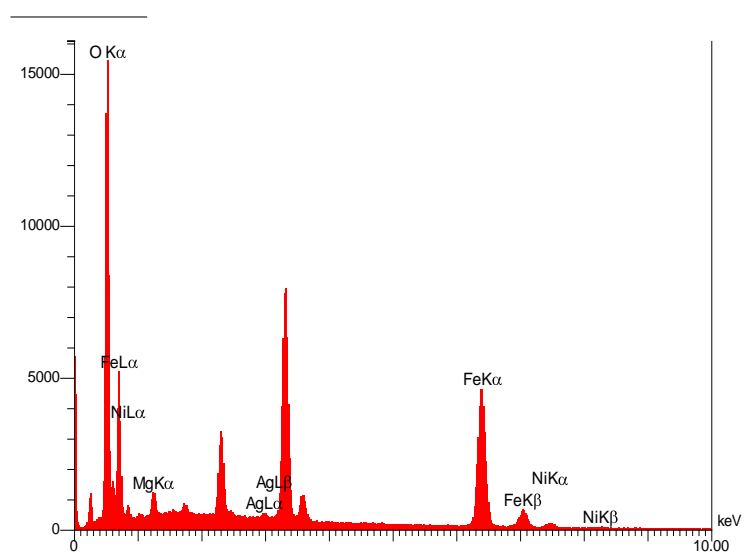

(b)

Figure 3-a- FE-SEM image, b-EDX spectra of the $\mathrm{Ni}_{0.31} \mathrm{Mg}_{0.15} \mathrm{Ag}_{0.04} \mathrm{Fe}_{2.5} \mathrm{O}_{4}$ magnetite NPs.

Figure-4 demonstrates the FT-IR absorption bands for the synthesized magnetite NPs. In Figure(4-a) that illustrates bare magnetite NPs, there are strong characteristic bands at around $600 \mathrm{~cm}^{-1}$ due to $(\mathrm{Fe}-\mathrm{O})$ bond; this proves that the main phase of the synthesized NPs is the magnetite $\left(\mathrm{Fe}_{3} \mathrm{O}_{4}\right)$ of spinel-type structure [7]. These characteristic peaks can be attributed to the lattice absorption of iron oxide [28]. There is also a small absorption band at $2360 \mathrm{~cm}^{-1}$ that can be attributed to the $\mathrm{CO}_{2}$ vibration. The broad absorption band at $3433 \mathrm{~cm}^{-1}$ indicates the existence of surface hydroxyl groups (O-H stretch) [7].

For the FT-IR spectra of the GA shown in Figure- (4-b), characteristic absorption bands were found at $\left(1616 \mathrm{~cm}^{-1}\right)$ as a broad peak and at $\left(1420 \mathrm{~cm}^{-1}\right)$ as narrower symmetrical peak, which can be attributed to the $\mathrm{C}-\mathrm{O}-\mathrm{O}$ bond stretching and carboxylic ion axial stretching, respectively. A broader absorption band is seen near $1030 \mathrm{~cm}^{-1}$, which could be attributed to the bond (COH stretching) [29]. The broadband at $3410 \mathrm{~cm}^{-1}$ represents the characteristic peak of the $-\mathrm{OH}$ groups stretch of polysaccharide [7].

It was observed that, following coating with GA (Figure 4-c), the characteristic absorption bands which appeared in (GA) spectrum (Figure 4-b) were noticed in the spectrum of GA-magnetite NPs (Figure- 4-c), confirming the fact that GA had successfully coated the surface of the synthesized magnetite NPs. 


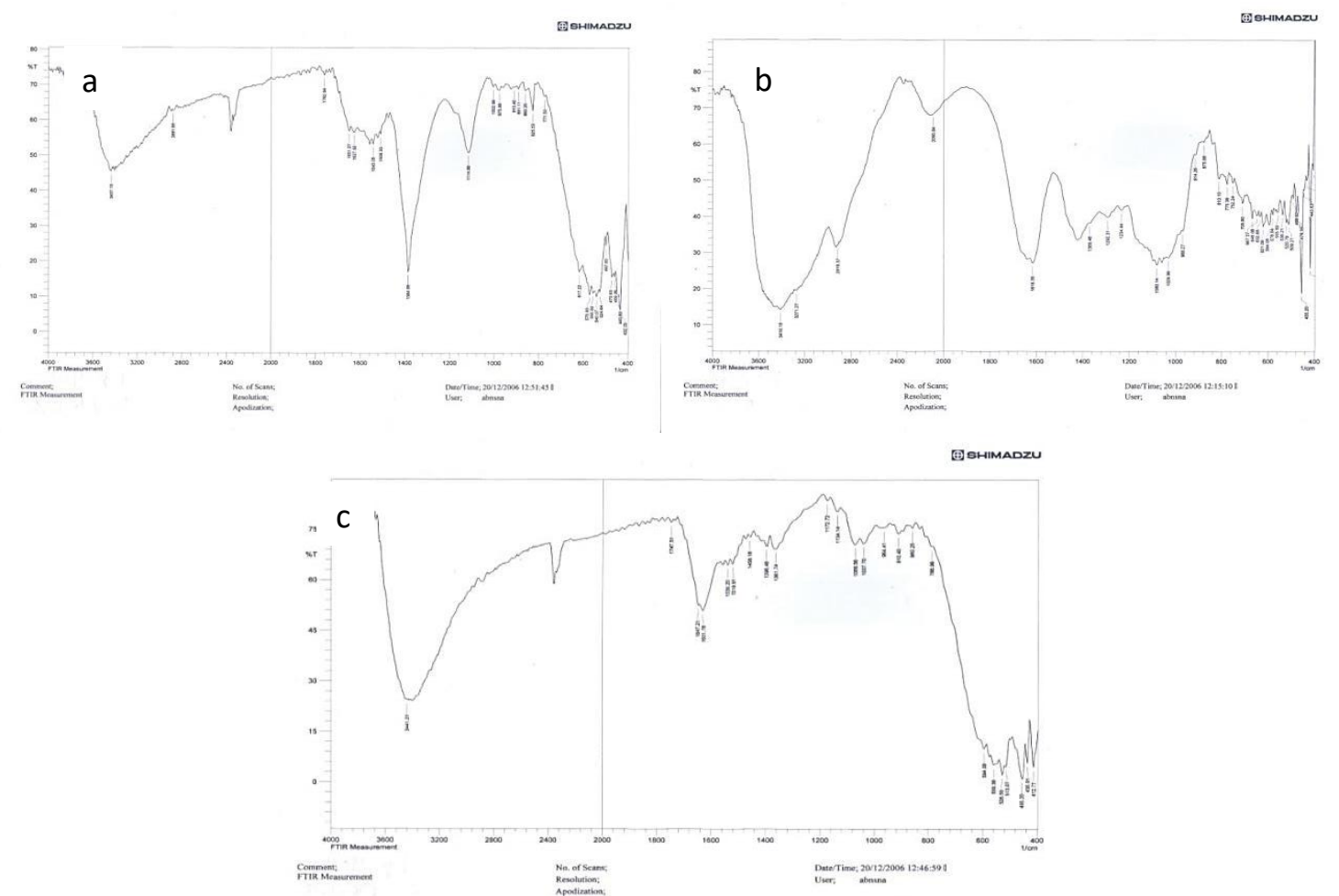

Figure 4-FT-IR spectra for a- bare magnetite NPs, b- GA, c- GA-magnetite NPs

Figure-5 shows $\mathrm{Pb}$ ion concentrations versus contact times between the GA-magnetite $\mathrm{NPs}$ and $\mathrm{Pb}$ ions. As it is seen, there is a considerable decrease in $\mathrm{Pb}$ ion concentration from 25 to $6.6 \mathrm{ppm}$ )at the time of $5 \mathrm{~min}$; this first fast decrease in heavy metal concentration is due to the high porosity of the synthesized nanoparticles, where the adsorption sites exist on their exterior, which facilitates the process of adsorption for the adsorbent particles to reach these active sites [30]. Moreover, coating with GA added a positive effect to the adsorption process, due to its carboxyl groups which acts as a binding agent in the process of adsorption. Also, GA solution is acidic [7], which is another factor for GA to enhance the adsorption process.

The second decrease of the $\mathrm{Pb}$ ion concentration was after $5 \mathrm{~min}$ which was a gradual decrease until the concentration reached $1.1 \mathrm{ppm}$ at the time of $25 \mathrm{~min}$. This is a proof that the synthesized magnetite NPs is efficient in removing $\mathrm{Pb}$ ions from aqueous solutions.

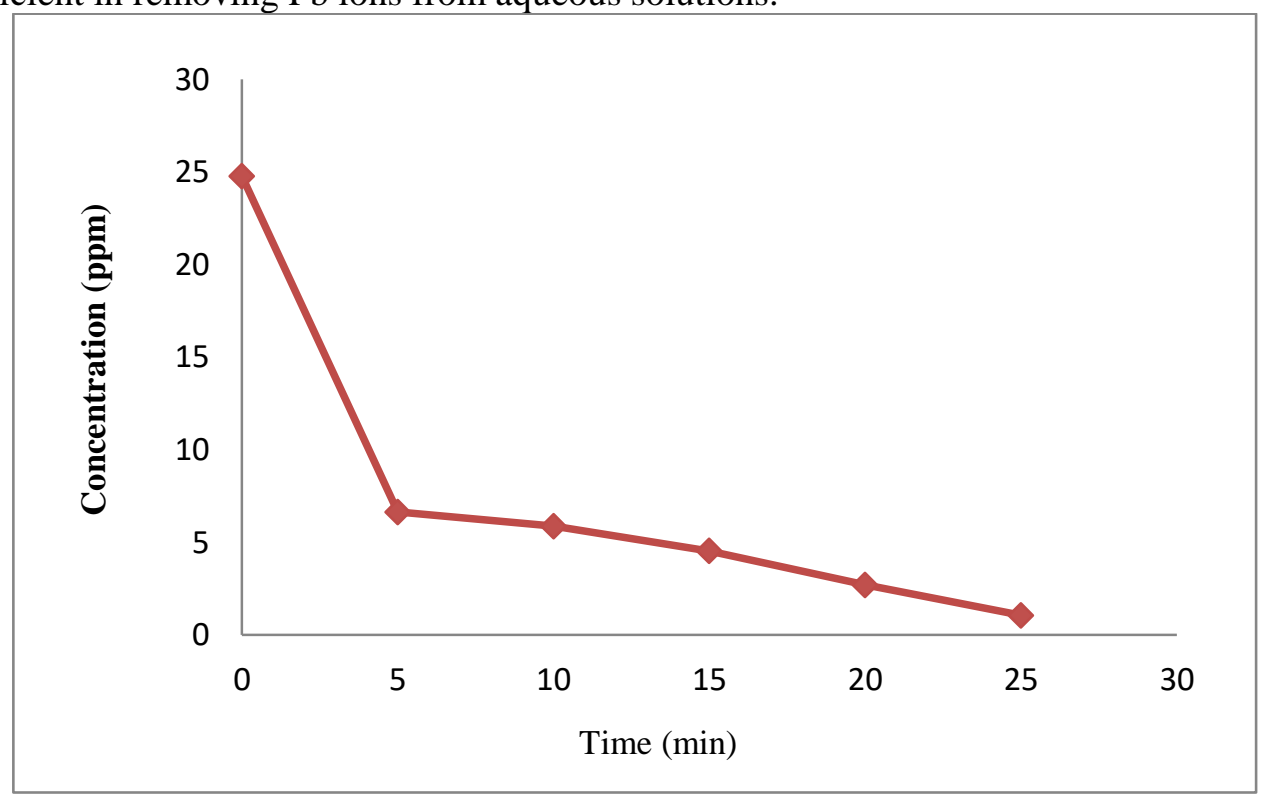

Figure 5-Pb ion concentration in solution 


\section{Conclusion}

$\mathrm{Ni}_{0.31} \mathrm{Mg}_{0.15} \mathrm{Ag}_{0.04} \mathrm{Fe}_{2.5} \mathrm{O}_{4}$ magnetite NPs were synthesized by the coprecipitation method. The average crystallite size was $28.57 \mathrm{~nm}$ which almost matches that measured by FE-SEM. The coating process with GA was achieved and ensured by the existence of the characteristic peaks of GA after coating, which are attributed to $\mathrm{C}-\mathrm{O}-\mathrm{O}$ band, carboxylic ion, and $\mathrm{OH}$ stretching, in addition to the $\mathrm{OH}$ groups stretch of polysaccharide. The porosity of the magnetite NPs, the acidity, and the carboxyl groups of GA, all added positive effects on the adsorption of $\mathrm{Pb}$ ions on the surface of the adsorbent, which highlights the way for a possibility of adsorption of other types of heavy metals.

\section{References}

1. Kobya, M., Demirbas, E., Senturk, E. and Ince, M. 2005. Adsorption of heavy metal ions from aqueous solutions by activated carbon prepared from apricot stone, Bioresour Technol, 96: 15181521.

2. Guo, S., Jiao, P., Dan, Z., Duan, N., Zhang, J., Chen, G., and Gao, W. 2017. Synthesis of magnetic bioadsorbent for adsorption of $\mathrm{Zn}(\mathrm{II}), \mathrm{Cd}(\mathrm{II})$ and $\mathrm{Pb}$ (II) ions from aqueous solution, Chem. Eng. Res. Des, 126: 217-231.

3. Kim, D.G., Kim, W.Y., Yun, C.Y., Son, D.J., Chang, D., Bae, H.S., Lee, Y.H., Sunwoo, Y. and Hong, K. H. 2013. Agro-industrial wastewater treatment by electrolysis technology, Int. J. Electrochem. Sci., 8: 9835-9850.

4. Vunain, E., Mishra, AK. and Mamba, BB. 2016. Dendrimers, mesoporous silicas and chitosanbased nanosorbents for the removal of heavy-metal ions: a review, Int. J. Biol. Macromol., 86: 570-586.

5. Grassi M., Kaykioglu, G., Belgiorno, V. and Lofrano, G. 2012. Removal of emerging contaminants from water and wastewater by adsorption process, in: Emerging Compounds Removal from Wastewater, Springer, 15-37, https://doi.org/10.1007/978-94-007-3916-1_2.

6. Teja, A.S. and Koh, P.-Y. 2009. Synthesis, properties, and applications of magnetic iron oxide nanoparticles, Prog. Cryst. Growth Charact. Mater., 55: 22-45.

7. Alzahrani, E. 2014. Gum Arabic-Coated Magnetic Nanoparticles For Methylene Blue Removal, IJIRSET, 3: 15118-15129.

8. Mao, P., Zhao, M., Zhang, F., Fang, Y., Phillips, G.O., Nishinari, K. and Jiang, F. 2013. Phase separation induced molecular fractionation of gum arabic-Sugar beet pectin systems. Carbohydrate Polymers., 98(1): 699-705.

9. Abuarra, A., Hashim, R., Kandaiya, S.B.S. and Tousi, E.T. 2014. Fabrication and characterization of gum Arabic bonded Rhizophora spp. Particleboards, Materials \& Design, 60: 108-115.

10. Ali, A., Maqboo, M., Alderson, P.G. and Zahid, N. 2013. Effect of gum arabic as an edible coating on antioxidant capacity of tomato (Solanum lycopersicum L.) fruit during storage, Postharvest Biology and Technology, 76: 119-124.

11. Kong, H., Yang, J., Zhang, Y., Fang, Y., Nishinari, K. and Phillips, G.O. 2014. Synthesis and antioxidant properties of gum arabic-stabilized selenium nanoparticles, International Journal of Biological Macromolecules, 65: 155-162.

12. Nishi, K. and Jayakrishnan, A. 2007. Self-gelling primaquine-gum arabic conjugate: an injectable controlled delivery system for primaquine, Biomacromolecules, 8(1): 84-90.

13. Lambert, J., Weinbreck, F. and Kleerebezem, M. 2008. In Vitro Analysis of Protection of the Enzyme Bile Salt Hydrolase against Enteric Conditions by Whey Protein- Gum Arabic Microencapsulation. Journal of agricultural and food chemistry, 56(18): 8360-8364.

14. Chockalingam, A.M., Babu, H.K.R.R., Chittor, R. and Tiwari, J.P. 2010. Gum arabic modified $\mathrm{Fe}_{3} \mathrm{O}_{4}$ nanoparticles cross linked with collagen for isolation of bacteria. Journal of nanobiotechnology, 8(1): 30-39.

15. Liu, J., Xie, TH., Deng, C., Du, KF., Zhang, N., Yu, JJ., Zou, YL. and Zhang, YK. 2014. Welan gum-modified cellulose bead as an effective adsorbent of heavy metal ions $\left(\mathrm{Pb}^{2+}, \mathrm{Cu}^{2+}\right.$, and $\mathrm{Cd}^{2+}$ )in aqueous solution. Sep Sci Technol, 49: 1096-1103.

16. Kattumuri, V., Katti, K., Bhaskaran, S., Boote, EJ., Casteel, SW. and Fent, GM. 2007. Gum arabic as a phytochemical construct for the stabilization of gold nanoparticles: in vivo pharmacokinetics and X-ray-contrast-imaging studies, Small, 3(3): 33-41. 
17. Kumar, MK., Reddy, ALM. And Ramaprabhu, S. 2008. Exfoliated single-walled carbon nanotube-based hydrogen sensor. Sens Actuators B, 130: 653-660.

18. Akartasse, N., Mejdoubi, E., Razzouki, B., Azzaoui, K., Jodeh, S., Hamed, O., Ramdani, M., Lamhamdi, A., Berrabah, M., Lahmass, I., Jodeh, W. and El Hajjaji, S. 2017. Natural product based composite for extraction of arsenic (III) from waste water, Chemistry Central Journal, 11(33): 1-13.

19. Arvand, M., Shemshadi, R., Efondiov, A.A., Zeynalov, N.A., Latify, L., Pourhabib, A. and farnoosh, R. 2010. Comparative Study for The Removal of $\mathrm{Hg}$ (II) From Aqueous Solutions by Adsorption on The Gum Arabic and Modified Gum Arabic, Asian Journal of Chemistry, 22( 8): 6289-6301.

20. Alzaidi, J., Alzahrani, E. and El-Mouhty, N.R.A. 2016. Chemical studies on the preparation of magnetic nanoparticles coated with glycine and its application for removal of heavy metals, Oriental Journal of Chemistry, 32(3): 1503-1513.

21. Al-Saadi, T.M., Abed, A.H., Salih, A.A. 2018. Synthesis and Characterization of $\mathrm{Al}_{\mathrm{y}} \mathrm{Cu}_{0.1} 5 \mathrm{Zn}_{0.85-}$ ${ }_{\mathrm{y}} \mathrm{Fe}_{2} \mathrm{O}_{4}$ Ferrite Prepared by the Sol-Gel Method, Int. J. Electrochem. Sci., 13: 8295 -8302.

22. Kazeminezhad, I. and Mosivand, S. 2014. Phase Transition of Electrooxidized $\mathrm{Fe}_{3} \mathrm{O}_{4}$ to $\gamma$ and $\alpha$ $\mathrm{Fe}_{2} \mathrm{O}_{3}$ Nanoparticles Using Sintering Treatment, Acta Physica Polonica A, 125(5): 1210-1214.

23. Hussain, F.I. and Tuamaa, F.M. 2016. Synthesis of Nano Compound $\left(\mathrm{Ba}_{1-\mathrm{x}} \mathrm{Sr}_{\mathrm{x}} \mathrm{TiO}_{3}\right)$ by Sol-Gel Method and Study its Structural Properties, Ibn Al-Haitham J. for Pure \& Appl. Sci. 29(1): 417427.

24. Carlos, L., Einschlag, F.S.G., González, M.C., and Mártire, D.O. 2013. Applications of Magnetite Nanoparticles for Heavy Metal Removal from Wastewater, IntechOpen, DOI: 10.5772/54608.

25. Al-Saadi, T.M. and Alsaady, L.J.k. 2015. Preparation of Silver anoparticles by Sol - Gel Method and Study their Characteristics, Ibn Al-Haitham J. for Pure \& Appl. Sci., 28(1): 301-307.

26. Sagadevan, S., Zaman, Z., Chowdhury and Rafique, R.F. 2017. Preparation and Characterization of Nickel ferrite Nanoparticles via Co-precipitation Method, Materials Research., http://dx.doi.org/10.1590/1980-5373-MR-2016-0533.

27. Newbury, D.E. 2009. Mistakes Encountered During Automatic Peak Identification of Minor and Trace Constituents in Electron-Excited Energy Dispersive X-Ray Microanalysis, SCANNING, 31: $1-11$.

28. Kadhima, R.M., Al-Abodi, E.E., and Al-Alawy, A.F. 2018. Citrate-coated magnetite nanoparticles as osmotic agent in a forward osmosis process, Desalination and Water Treatment, 115: 45-52.

29. Abreu, F.O.M.d.S., Silva, N.A.d., Sipauba, M.d.S., Pires, T.F.M., Bomfim, T.A., Junior, O.A.d.C.M., and Forte, M.M.d.C. 2018. Chitosan and gum arabic nanoparticles for heavy metal adsorption, ISSN, 28(3): 231-238.

30. Banerjee, Sh.S., and Chen, D.-H. 2007. Fast removal of copper ions by gum arabic modified magnetic nano-adsorbent, Journal of Hazardous Materials, 147: 792-799. 